\title{
Long-term results and predictors of survival after surgical resection of patients with lung cancer and interstitial lung diseases
}

\author{
Toshihiko Sato, MD, PhD, ${ }^{\mathrm{a}}$ Atsushi Watanabe, $\mathrm{MD}, \mathrm{PhD},{ }^{\mathrm{b}}$ Haruhiko Kondo, $\mathrm{MD}, \mathrm{PhD}$, \\ Masato Kanzaki, MD, PhD, ${ }^{\mathrm{d}}$ Kenichi Okubo, $\mathrm{MD}, \mathrm{PhD},{ }^{\mathrm{e}}$ Kohei Yokoi, MD, PhD, \\ Kazuya Matsumoto, MD, PhD, ${ }^{\mathrm{g}}$ Takashi Marutsuka, MD, PhD, ${ }^{\mathrm{h}}$ Hirohiko Shinohara, MD, PhD, \\ Satoshi Teramukai, PhD, ${ }^{\mathrm{j}}$ Kazuma Kishi, MD, PhD, ${ }^{\mathrm{k}}$ Masahito Ebina, MD, PhD, \\ Yukihiko Sugiyama, $\mathrm{MD}, \mathrm{PhD},{ }^{\mathrm{m}}$ Okumora Meinoshin, $\mathrm{MD}, \mathrm{PhD},{ }^{\mathrm{n}}$ and \\ Hiroshi Date, MD, PhD, ${ }^{a}$ for the Japanese Association for Chest Surgery
}

Objectives: Patients with interstitial lung diseases have a poor prognosis and are at increased risk of developing lung cancer. We evaluated the survival and predictors of survival after surgical resection in lung cancers in patients with interstitial lung diseases.

\begin{abstract}
Methods: We retrospectively analyzed data from 1763 patients with non-small cell lung cancer with a clinical diagnosis of interstitial lung disease who underwent pulmonary resection between 2000 and 2009 at 61 Japanese institutions.
\end{abstract}

Results: Male patients $(90.4 \%)$ and smokers $(93.8 \%)$ were in the majority. The overall 5-year survival was $40 \%$. The 5 -year survivals were $59 \%, 42 \%, 43 \%, 29 \%, 25 \%, 17 \%$, and $16 \%$ for patients with stage Ia, Ib, IIa, IIb, IIIa, IIIb, and IV, respectively. Patients with stage IA had a 5 -year survival of $33.2 \%, 61.0 \%$, and $68.4 \%$ in the wedge resection, segmentectomy, and lobectomy groups, respectively (log-rank test, $P=.0038)$. The leading cause of death was cancer recurrence $(50.2 \%)$, followed by respiratory failure $(26.8 \%)$. Wedge resection reduced mortality due to respiratory failure when compared with that of lobectomy $(P=.022)$. Multivariable analysis revealed that the type of surgical procedure, predicted percent vital capacity, and tumor locations were independent predictors for survival. The 5-year survival was $20 \%$ for patients with stage Ia with a predicted percent vital capacity of $80 \%$ or less, and $64.3 \%$ for patients with a predicted percent vital capacity greater than $80 \%$ (log-rank test, $P<.0001)$.

Conclusions: In these patients, there are competing risks of death. Wedge resection reduced death caused by respiratory failure but resulted in poorer long-term prognosis than lobectomy. For patients with poor predictors of survival, such as predicted percent vital capacity of $80 \%$ or less, surgical resection should be limited. (J Thorac Cardiovasc Surg 2015;149:64-70)

\footnotetext{
From the Department of Thoracic Surgery, ${ }^{\text {a }}$ Kyoto University, Kyoto, Japan; Department of Thoracic Surgery, ${ }^{b}$ Sapporo Medical University School of Medicine and Hospital, Sapporo, Japan; Department of Thoracic Surgery, ${ }^{\mathrm{c}}$ Kyorin University School of Medicine, Tokyo, Japan; Department of Surgery I, ${ }^{\mathrm{d}}$ Tokyo Women's Medical University Hospital, Tokyo, Japan; Department of Thoracic Surgery, ${ }^{\mathrm{e}}$ Tokyo Medical and Dental University, Tokyo, Japan; Department of Thoracic Surgery, Nagoya University Hospital, Nagoya, Japan; Kishiwada City Hospital, ${ }^{\mathrm{g}}$ Kishiwada, Japan; Kumamoto Chuo Hospital, ${ }^{\mathrm{h}}$ Kumamoto, Japan; Niigata University Graduate School of Medical and Dental Sciences of Thoracic and Cardiovascular Surgery, Niigata, Japan; Innovative Clinical Research Center, ${ }^{\mathrm{j}}$ Kanazawa University, Kanazawa, Japan; Department of Respiratory Medicine, ${ }^{\mathrm{k}}$ Respiratory Center, Toranomon Hospital, Tokyo, Japan; Respiratory Center, ${ }^{1}$ Tohoku Pharmaceutical University Hospital, Sendai, Japan; Department of Pulmonary Medicine, ${ }^{\mathrm{m}} \mathrm{Jichi}$ Medical University, Tochigi, Japan; and Department of General Thoracic Surgery, ${ }^{\mathrm{n}}$ Oosaka Medical Center for Cancer and Cardiovascular Diseases, Oosaka, Japan.

Disclosures: Yukihiko Sugiyama reports lecture and consulting fees from Nippon Behringer Ingelheim and lecture fees from Shionogi Pharmaceutical Company. The other authors have nothing to disclose with regard to commercial support.

Read at the 94th Annual Meeting of The American Association for Thoracic Surgery, Toronto, Ontario, Canada, April 26-30, 2014.

Received for publication April 9, 2014; revisions received Aug 21, 2014; accepted for publication Aug 25, 2014; available ahead of print Oct 16, 2014.

Address for reprints: Hiroshi Date, MD, PhD, 54 Shogoin Kahawara-cho Sakyoku Kyoto 606-8507, Japan (E-mail: hdate@kuhp.kyoto-u.ac.jp).

0022-5223/\$36.00

Copyright (c) 2015 by The American Association for Thoracic Surgery

http://dx.doi.org/10.1016/j.jtcvs.2014.08.086
}

See related commentary on pages 71-2.

Supplemental material is available online.

Interstitial lung diseases (ILDs) are associated with an increased risk of lung cancer, ${ }^{1,2}$ and the prevalence of lung cancer ranges from $6 \%$ to $17 \%$ during the course of ILDs. In these patients, Ozawa and colleagues ${ }^{3}$ reported that the cumulative incidence rate of lung cancer was approximately $3.3 \%, 15.4 \%$, and $54.7 \%$ at 1,5 , and 10 years, respectively. ${ }^{3}$ However, the contribution of anticancer therapies is unclear because these therapies may trigger fatal complications, such as acute exacerbation (AE), and are confounded by the progressive nature and poor prognoses of ILDs. Although the survival of this group of patients was considered to be poorer than that of other 


$$
\begin{aligned}
& \text { Abbreviations and Acronyms } \\
& \begin{aligned}
\mathrm{AE} & =\text { acute exacerbation } \\
\mathrm{CI} & =\text { confidence interval } \\
\mathrm{CT} & =\text { computed tomography } \\
\mathrm{DLCO} & =\text { carbon monoxide diffusing capacity } \\
\mathrm{FEV} 1 & =\text { forced expiratory volume in } 1 \text { second } \\
\mathrm{FVC} & =\text { forced vital capacity } \\
\mathrm{ILD} & =\text { interstitial lung disease } \\
\mathrm{IPF} & =\text { idiopathic pulmonary fibrosis } \\
\mathrm{OR} & =\text { odds ratio } \\
\mathrm{UIP} & =\text { usual interstitial pneumonia } \\
\% \mathrm{VC} & =\text { percent vital capacity }
\end{aligned}
\end{aligned}
$$

patient cohorts with ILDs, no reliable figures based on a large study have been reported to address this problem.

In our previous report using data from 61 institutes in Japan on 1763 patients with lung cancer who had ILDs, we studied the morbidity and mortality rate of patients with pulmonary resection and identified 7 risk factors for postoperative $\mathrm{AE}$ of pulmonary fibrosis. ${ }^{4}$ By using the same cohort, we have analyzed their long-term survival and the probable factors influencing their survival.

\section{PATIENTS AND METHODS}

The patients' basic backgrounds are shown in Table 1. The patient cohort was identical to that used in our previous study. Briefly, the majority of patients were men $(90.4 \%)$ and ex- or current smokers $(93.8 \%)$. Usual interstitial pneumonia (UIP) diagnoses were made in $73.7 \%$ of the patients by computed tomography (CT) scan. Squamous cell carcinoma was the most common type of lung cancer $(46.9 \%)$, followed by adenocarcinoma $(41.4 \%)$. Most of the patients had stage I disease (1028 cases). Lobectomy was the most common surgical procedure ( 1236 cases, $70.4 \%$ ), followed by wedge resection ( 275 cases, $15.7 \%$ ), segmentectomy (150 cases, $8.6 \%$ ), bilobectomy (61 cases, $3.4 \%$ ), and pneumonectomy (33 cases, $1.9 \%$ ). TNM stages were based on the classification of the malignant tumors by the Union for International Cancer Control (6th edition). ${ }^{5}$

Inclusion criteria for the patients have been described. ${ }^{4}$ Patients with ILDs and non-small-cell lung cancer who had undergone pulmonary resection other than surgical biopsy for diagnostic purpose were included. ILDs were confirmed on the basis of a radiologic finding on the chest CT scan according to the clinical criteria proposed by the Japanese Respiratory Society, and these criteria are consistent with the 2011 guidelines of the American Thoracic Society. ${ }^{6}$ The cases were categorized into 2 groups according to their radiologic appearance on CT scan: (1) UIP pattern: This group is characterized by the presence of basal-dominant reticular opacities and predominantly basal and subpleural distribution of honeycomb lesions with multiple equal-sized cystic lesions of 2 to $10 \mathrm{~mm}$ in diameter with a thick wall; and (2) non-UIP pattern: This group is characterized by the presence of basal-predominant ground glass opacities and infiltrative shadows inconsistent with UIP patterns. The patient data were retrospectively accumulated between January 2000 and December 2009 , which is more than the 3 consecutive years at 61 hospitals throughout Japan. The number of patients at each institute varied from 4 to 133; the institutes with a small number patients were the result of more than 3 consecutive years of observation. We were unable to set or investigate the selection criteria for the surgical procedures in each institute.
The study protocol was approved by the institutional review boards of all participating hospitals, including that of the Ethics Committee, Kyoto University Graduate School and Faculty of Medicine (Approval Number: E-982).

The primary end point was overall survival time, defined as the time from surgical procedure to death from any cause. Postoperative patient information, including cancer recurrence site, exacerbation of IP, and cause of death, was also collected until March 2011, the end of data collection.

\section{Statistical Analyses}

Survival curves were estimated using the Kaplan-Meier method. The variables in Table E1 were analyzed for multivariate Cox regression analysis to identify probable predictors of survival. Klebs von Lungen-6, carcinoembryonic antigen, partial pressure of carbon dioxide, partial pressure of oxygen, carbon monoxide diffusing capacity (DLCO), and percent predicted DLCO were not included in the analysis because of missing data more than $5 \%$. Forced expiratory volume in 1 second (liters) was eliminated because it is correlated with predicted percent vital capacity $(\%$ VC) (Pearson's correlation coefficient $=0.621)$. Cox proportional hazards regression analysis was used to estimate the hazard ratio and the $95 \%$ confidence interval (CI) of each factor. Multivariate Cox regression analysis with backward elimination was performed to select significant prognostic factors. To examine the relationship between surgical procedures and cause of death, multivariate logistic regression analysis that was adjusted for the significant prognostic factors was used. All reported $P$ values were 2 -sided, and a value less than .05 was used for variable selection. Data management and statistical analyses were conducted in the Department of Clinical Trial Design and Management, Translational Research Center, Kyoto University Hospital. All statistical analyses were performed using SAS version 9.3 and JMP version 8.1 (SAS Institute, Inc, Cary, NC).

\section{RESULTS}

\section{Cause of Death}

Death due to cancer was the main cause of mortality $(378 / 753,50.2 \%)$, and death due to respiratory failure $(202 / 753,26.8 \%)$ was the second most common cause of death. Details of the respiratory failure death were as follows; 72 patients $(35.6 \%)$ died of $\mathrm{AE}$ of interstitial pneumonia within 30 days from the operation, and 117 patients died of AE during the following period (Table 2).

\section{Identification of Prognostic Factors}

Cox regression analysis identified that age, sex, pTNM stages, $\% \mathrm{VC}$, type of surgical procedure, and tumor location were independent predictors for survival (Table 3). As for surgical procedures, the hazard ratios of the segmentectomy and lobectomy groups versus the wedge resection group were 0.957 (95\% CI, 0.698-1.313; $P=.786)$ and 0.704 (95\% CI, 0.565-0.878; $P=.002$ ), respectively (Table 3).

\section{Survival}

The 5-year survivals were $59 \%, 42 \%, 43 \%, 29 \%, 25 \%$, $17 \%$, and $17 \%$ for pTNM stages Ia, Ib, IIa, IIb, IIIa, IIIb, and IV, respectively (Figure 1, A). The 5-year survivals in patients with pathologic stage Ia were estimated to be $33.2 \%$ for the wedge resection group, $61 \%$ for the segmentectomy group, and $68.4 \%$ for the lobectomy group 
TABLE 1. Patients' characteristics

\begin{tabular}{lcc}
\hline \multicolumn{1}{c}{ Categories } & Cases $(\%)$ & Median (range) \\
\hline Age (y) & 1763 & $71(36-88)$ \\
Sex (male/female) & $1593(90.4) / 170(9.6)$ & \\
Smoking history & & \\
Never smoker & $109(6.2)$ & \\
Ex/current smoker & $1006 / 632$ & \\
Brinkman index* & 1742 & \\
Radiologic diagnosis & & \\
UIP/non-UIP pattern & $1300(73.7) / 463(26.3)$ & \\
Pathology & & \\
Squamous cell carcinoma & $816(46.9)$ \\
Adenocarcinoma & $721(41.4)$ \\
Large cell carcinoma & $64(3.7)$ & \\
Pathologic stage $\dagger$ & & \\
1/2/3/4 & $1028 / 311 / 358 / 34$ \\
Surgical procedures & \\
Wedge resection & $275(15.7)$ \\
Segmentectomy & $150(8.6)$ \\
Lobectomy & $1236(70.4)$ \\
Bilobectomy & $61(3.4)$ \\
Pneumonectomy & $33(1.9)$ \\
\hline
\end{tabular}

UIP, Usual interstitial pneumonia. *Brinkman Index: The numbers of cigarettes smoked per day times years. $\dagger$ TNM stages based on the classification of the malignant tumors by the Union for International Cancer Control, 6th edition

(Figure 1, B). Survival of patients with pTNM stage Ia who had wedge resection was poorer than that of the lobectomy group $(P<.0008)$ but not significantly different from that of the segmentectomy group $(P<.365)$ (Figure $1, B)$.

For all patients, the 5-year survivals of those with lower $\% \mathrm{VC}(\leq 80 \%)$ and normal $\% \mathrm{VC}(>80 \%)$ were estimated as $20.8 \%$ and $43.8 \%$, respectively (log-rank test, $P<.0001)$. For patients with stage IA, the 5-year survivals of those with lower $\% \mathrm{VC}(\leq 80 \%)$ and normal $\% \mathrm{VC}$ $(>80 \%)$ were estimated as $20 \%$ and $64.3 \%$, respectively (log-rank test, $P<.0001$ ) (Figure 1, $C$ and $D$ ).

\section{Surgical Procedures and Cause of Death in Patients With Stage IA}

Patients with stage IA were selected to evaluate the influence of the types of surgical procedure on the cause of death, using logistic regression analyses that adjusted for age, sex, and \%VC. In cases involving death due to cancer, wedge resection and segmentectomy were associated

TABLE 2. Cause of death and details of respiratory failure deaths

\begin{tabular}{llc}
\hline & \multicolumn{1}{c}{ Categories } & Cases (\%) \\
\hline Cause of death & Lung cancer & $378(50.2)$ \\
& Respiratory failure & $202(26.8)$ \\
& Other & $173(23.0)$ \\
Death due to respiratory failure & Postoperative AE* & $72(35.6)$ \\
& Chronic exacerbation $\dagger$ & $117(57.9)$ \\
& Other & $13(6.4)$ \\
\hline
\end{tabular}

$A E$, Acute exacerbation. *Interstitial pneumonia within 30 days after surgery. $\dagger$ Exacerbation of interstitial pneumonia occurring $\geq 31$ days after the operation.
TABLE 3. Cox proportional hazards regression analysis for survival

\begin{tabular}{|c|c|c|c|c|}
\hline Categories & Cases & Hazard ratio & $95 \% \mathrm{CI}$ & $P$ value \\
\hline Age (y) & 1656 & 1.017 & $1.005-1.028$ & .004 \\
\hline \multicolumn{5}{|l|}{ Sex } \\
\hline Male & 1497 & 1.000 & - & - \\
\hline Female & 159 & 0.711 & $0.535-0.945$ & .019 \\
\hline \multicolumn{5}{|l|}{ Pathologic stage } \\
\hline Ia & 528 & 1.000 & - & 一 \\
\hline $\mathrm{Ib}$ & 469 & 1.728 & $1.381-2.163$ & $<.001$ \\
\hline IIa & 65 & 2.009 & $1.352-2.984$ & $<.001$ \\
\hline $\mathrm{IIb}$ & 226 & 2.497 & $1.933-3.225$ & $<.001$ \\
\hline IIIa & 233 & 3.708 & $2.884-4.767$ & $<.001$ \\
\hline $\mathrm{IIIb}$ & 102 & 3.204 & $2.354-4.361$ & $<.001$ \\
\hline IV & 33 & 3.774 & $2.438-5.841$ & $<.001$ \\
\hline$\% \mathrm{VC}$ & 1656 & 0.980 & $0.975-0.984$ & $<.001$ \\
\hline \multicolumn{5}{|l|}{ Procedures } \\
\hline Wedge resection & 250 & 1.000 & - & - \\
\hline Segmentectomy & 137 & 0.957 & $0.698-1.313$ & .786 \\
\hline Lobectomy & 1209 & 0.704 & $0.565-0.878$ & .002 \\
\hline $\begin{array}{l}\text { Bilobectomy/ } \\
\text { pneumonectomy }\end{array}$ & 60 & 0.745 & $0.494-1.123$ & .159 \\
\hline \multicolumn{5}{|l|}{ Tumor location } \\
\hline Upper lobe & 649 & 1.000 & - & - \\
\hline Middle lobe & 74 & 1.421 & $0.977-2.065$ & .066 \\
\hline Lower lobe & 928 & 1.409 & $1.202-1.652$ & $<.001$ \\
\hline Multiple & 5 & 0.000 & N/A & N/A \\
\hline
\end{tabular}

with poor outcome; the odds ratio (OR) of wedge resection versus lobectomy was 2.98 (95\% CI, 1.56-5.68; $P=.001)$, and the OR of segmentectomy versus lobectomy was 2.56 (95\% CI, 1.15-5.67; $P=.021)$. In cases involving respiratory failure, the $\mathrm{OR}$ of wedge resection versus lobectomy was 0.35 (95\% CI, $0.15-0.82 ; P=.015)$, and the OR of segmentectomy versus lobectomy was 0.80 $(95 \%$ CI, 0.32-2.01; $P=.641)$.

\section{DISCUSSION}

Determining the surgical indication for patients with lung cancer with ILDs is difficult. In addition to their impaired pulmonary reserve, it is not clear whether pulmonary resection is beneficial or harmful for each individual. The median survival of the patients with idiopathic pulmonary fibrosis (IPF) reportedly ranges from 2 to 4.2 years from the date of diagnosis. ${ }^{6-8}$ Although there is a general understanding that the prognosis of patients with lung cancer with ILDs is poor, existing evidence to support these conclusions was based on a few studies with a comparatively small number of patients (14-56). ${ }^{9-16}$ Saito and colleagues ${ }^{9}$ reported that the 5-year survival of patients with stage IA lung cancer with IPF was $54.2 \%$, and the propensity-matched analysis confirmed that IPF was the only significant prognostic factor. Watanabe and colleagues ${ }^{10}$ reported a 5 -year survival of $61.6 \%$ after pulmonary resection for patients with stage Ia and stage Ib. Our study elucidated the 5-year survival of this group 

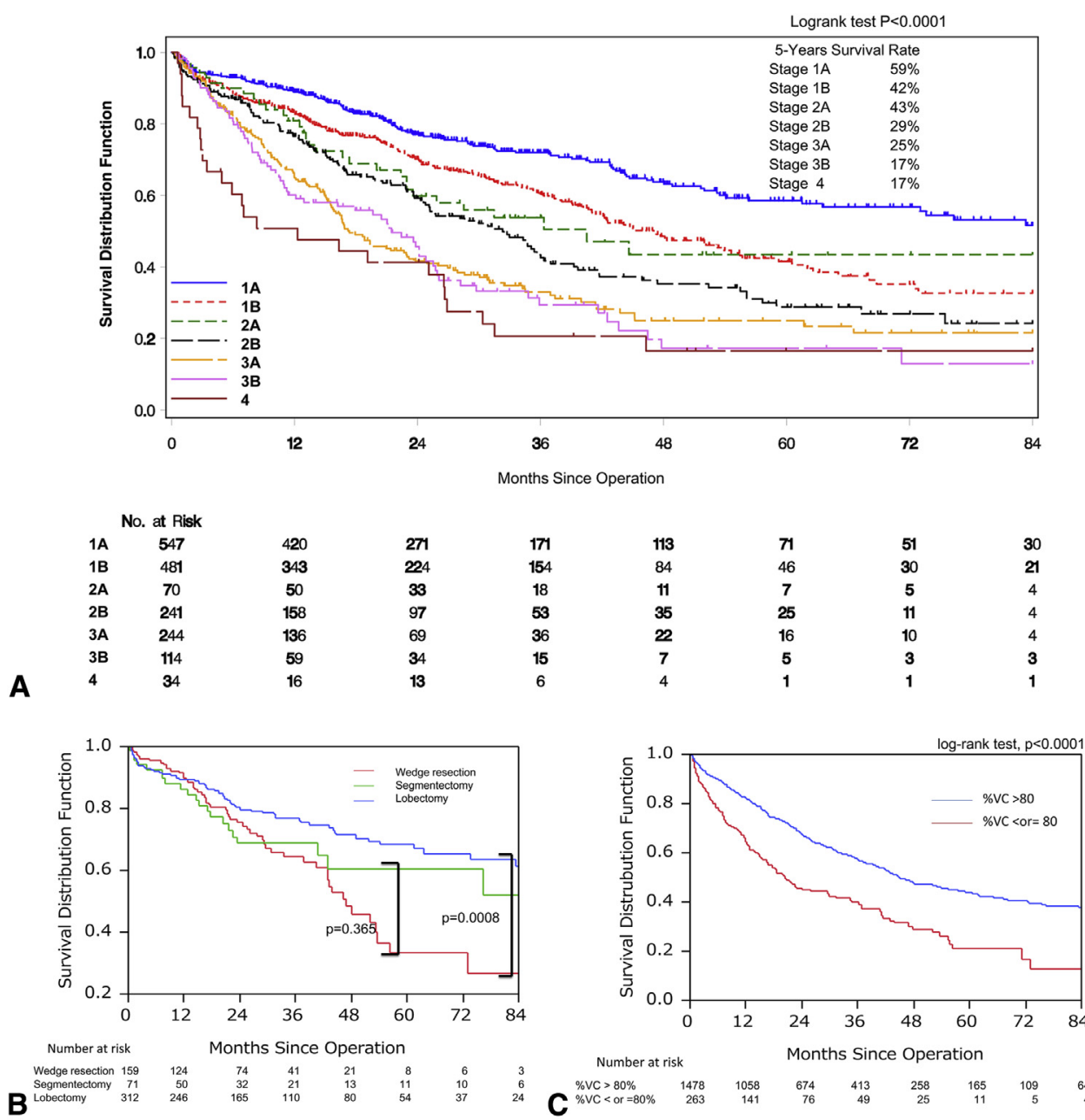

\section{B}

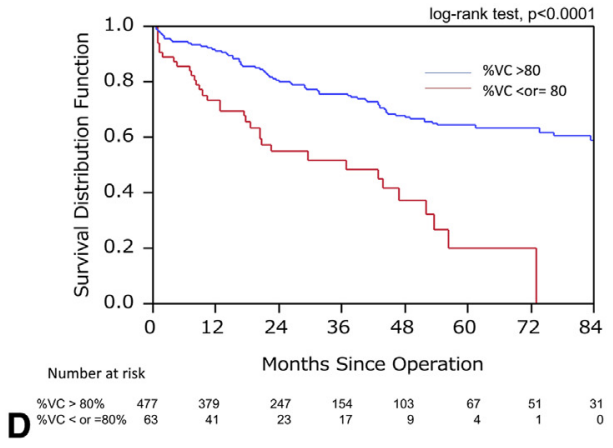

FIGURE 1. A, Overall survival of patients with ILDs who underwent pulmonary resection. B, Survival of the wedge resection, segmentectomy, and lobectomy groups in patients with stage IA; 5-year survival of each group was $29.2 \%, 60.0 \%$, and $68.6 \%$, respectively. No significant difference was found between the wedge resection and segmentectomy groups (log-rank $P=.365)$. C, For all stages, 5 -year survival of patients with lower $\% \mathrm{VC}(\leq 80 \%)$ and normal $\% \mathrm{VC}(>80 \%)$ was $43.8 \%$ and $20.8 \%$, respectively (log-rank test, $P<.0001)$. D, For patients with stage IA, 5 -year survival of patients with lower $\%$ $\mathrm{VC}(\leq 80 \%)$ and normal $\% \mathrm{VC}(>80 \%)$ was $64.3 \%$ and $20.0 \%$, respectively (log-rank test, $P<.0001) . \% V C$, Percent vital capacity.

of patients for the various cancer stages and found that the survival was substantially poorer than the recent figures reported by the Japanese Joint Committee for Lung Cancer Registration for overall patients $(86.8 \%, 73.9 \%, 61.6 \%$, $49.8 \%, 40.9 \%, 27.8 \%$, and $27.9 \%$ for pathologic stage Ia, Ib, IIa, IIb, IIIa, IIIb, and IV, respectively). ${ }^{17}$ This poorer survival is likely due to the high incidence of cancer recurrence, combined with the poor survival of ILD itself. Watanabe and colleagues ${ }^{9}$ and Okamoto and colleagues ${ }^{16}$ reported an increased cancer recurrence in patients with IPF, but the recurrence rate has not been reported. We determined that recurrence was the main cause of death 
TABLE 4. Logistic regression analysis in patients with stage $1 \mathrm{~A}$, adjusted for age, sex, and predicted percent of vital capacity

\begin{tabular}{|c|c|c|c|c|c|}
\hline Cause of death & Procedures & Cases (\%) & OR & $\mathbf{9 5} \% \mathbf{C I}$ & $P$ value \\
\hline \multirow[t]{3}{*}{ Cancer } & Lobectomy & $20 / 312(6.4)$ & 1 & - & - \\
\hline & Segmentectomy & $12 / 71(16.9)$ & 2.56 & $1.15-5.67$ & .021 \\
\hline & Wedge resection & $26 / 159(16.4)$ & 2.98 & $1.56-5.68$ & .001 \\
\hline \multirow[t]{3}{*}{ Respiratory failure } & Lobectomy & $31 / 312(9.9)$ & 1 & - & - \\
\hline & Segmentectomy & $7 / 71(9.9)$ & 0.80 & $0.32-2.01$ & .641 \\
\hline & Wedge resection & $10 / 159(6.3)$ & 0.35 & $0.15-0.82$ & .015 \\
\hline
\end{tabular}

$C I$, Confidence interval; $O R$, odds ratio.

and was approximately twice as high as that of respiratory failure, indicating the importance of oncologic control for survival.

As for predictors of the patients' survival, multivariable analysis revealed that low $\% \mathrm{VC}$ was an independent and strong predictor together with the age, sex, pTNM, type of surgical procedure, and tumor location. It is rather appalling that the 5-year survival of the patients with stage IA whose $\% \mathrm{VC}$ was less than $80 \%$ was as poor as $20 \%$. For this group of patients, the decision to perform pulmonary resection should be considered carefully. The natural course of patients with ILDs varies in their disease progression: Some are stable for years, whereas others exhibit more rapid deterioration. ${ }^{6}$ Nishiyama and colleagues $^{18}$ claimed the median survival of patients with a modified Medical Research Council score of 0 (not troubled with breathlessness except with strenuous exercise) and 1 (troubled by shortness of breath when hurrying on the level or walking up a slight hill) was estimated at $66.7 \% .{ }^{19}$ Because we showed that cancer was the primary cause of death, lobectomy should be the first choice for those with preserved \% VC and good physical status.

Although DLCO is a well-known survival predictor for patients with ILDs, we did not include this in the analysis because of too many missing values, which indicates that DLCO measurement in clinical practice is costly and not common. Impaired right heart function and pulmonary hypertension are known to be associated with the poor prognosis of patients with pulmonary fibrosis. ${ }^{20}$ However, preliminary research showed that few patients had the preoperative assessment; thus, we did not include these variables in the study questionnaires.

Patients with lung cancer and ILDs have a high incidence of morbidity and mortality in the perioperative period and a poor long-term prognosis due to both cancer recurrence and deterioration of interstitial pneumonia. To achieve better survival in this group of patients, we propose 2 strategies; one is to decrease the incidence of perioperative fatal complications, namely, AE of IP, and the other is to decrease cancer recurrence. Since Kutlu and colleagues ${ }^{21}$ pointed out the high incidence of morbidity and mortality of patients with ILDs in the perioperative periods, AE has begun to be a concern of surgeons. ${ }^{1,22}$ Among the problems regarding morbidity, $\mathrm{AE}$ is an important issue because it has serious consequences once it occurs. We reported that the incidence of operation-induced $\mathrm{AE}$ in this patient group is up to $9.3 \%$ and the mortality rate is as high as $43.9 \% .{ }^{4}$ No effective prophylactics or measures for $\mathrm{AE}$ prevention are available so far; only wedge resection may reduce the risk of $\mathrm{AE}$. We reported that segmentectomy and lobectomy increase the risk of $\mathrm{AE}$ compared with wedge resection (OR, 3.83; 95\% CI, 1.941-7.567; $P=.0005) .{ }^{4}$ However, as we have shown in the present study, long-term survival of patients with stage Ia disease who underwent wedge resections was poorer than that of patients who underwent lobectomy (Figure 1, B). The estimated survival curve of the wedge resection group crossed that of the lobectomy group 1 year after the surgery, and the survival of the wedge resection group was significantly poorer than that of the lobectomy group (log-rank test, $P=.0008$ ). These observations can be explained by the fact that the wedge resection group was less likely to develop AE but had a higher cancer recurrence rate than the lobectomy group. Of note, the curves of the wedge resection group and segmentectomy groups did cross 30 months after the operation, and the survival of both groups showed no significant difference (log-rank test, $P=.365$ ). Furthermore, multivariate logistic regression analysis on the cause of death (Table 4) showed that the wedge resection and segmentectomy groups had less favorable oncologic outcomes when compared with the lobectomy group. In terms of death caused by respiratory failure, the wedge resection showed a favorable effect when compared with the lobectomy group $(P=.022)$, but the segmentectomy group showed no significant effect $(P=.580)$. These results implied that segmentectomy seemed to not be beneficial in controlling cancer or reducing respiratory failure. On the other hand, wedge resection may reduce the risk of respiratory failure but resulted in more cancer deaths than in the lobectomy group. Cancer control was shown as the key to achieve better survival; therefore, we believe that lobectomy should be selected except in patients with a high risk of AE. Our former study showed that the patients with a combination of a history of AE of ILDs, preoperative steroid use, UIP pattern on $\mathrm{CT}$, and male gender proved to be at high risk for $\mathrm{AE}^{4}{ }^{4}$ 


\section{Study Limitations}

There are study limitations that should be considered in the interpretation of the results. First, this was a retrospective cohort study, which may not necessarily reflect the characteristics of the entire population with this disease. Second, the primary inclusion criterion was the appearance of ILDs on CT. Although radiologic diagnoses were made by each individual institute following criteria based on widely used guidelines, the diagnosis of interstitial pneumonia may vary among institutes. We could not include the assessment of patients' physical status, such as the Borg Scale, 6-minute walk test, and modified Medical Research Council score, which reportedly correlate well with patient survival. ${ }^{5,17,23}$

\section{CONCLUSIONS}

In this study, we have investigated the cause of death and the long-term survival of patients with lung cancer concomitant with ILDs who underwent pulmonary resection. We showed that cancer was the primary cause of death, and to achieve better surgical outcomes for this group of patients, lobectomy should be the first choice for those with preserved $\% \mathrm{VC}$.

The authors thank Kyosuke Kimura, Asakazu Ogasawara, and the participating investigators for data collection and management.

\section{References}

1. Kumar P, Goldstraw P, Yamada K, Nicholson AG, Wells AU, Hansell DM, et al. Pulmonary fibrosis and lung cancer: risk and benefit analysis of pulmonary resection. J Thorac Cardiovasc Surg. 2003;125:1321-7.

2. Raghu G, Nyberg F, Morgan G. The epidemiology of interstitial lung disease and its association with lung cancer. Br J Cancer. 2004;91(Suppl 2):S3-10.

3. Ozawa Y, Suda T, Naito T, Enomoto N, Hashimoto D, Fujisawa T, et al. Cumulative incidence of and predictive factors for lung cancer in IPF. Respirology. 2009; 14:723-8.

4. Sato T, Teramukai S, Kondo H, Watanabe A, Ebina M, Kishi K, et al. Impact and predictors of acute exacerbation of interstitial lung diseases after pulmonary resection for lung cancer. J Thorac Cardiovasc Surg. 2014;147:1604-11.e3.

5. Sobin LH, Wittekind C, eds. International Union Against Cancer (UICC), TNM Classification of Malignant Tumors. 6th ed. New York: Wiley-Liss; 2002:99-103.

6. Raghu G, Collard HR, Egan JJ, Martinez FJ, Behr J, Brown KK, et al. An official ATS/ERS/JRS/ALAT statement: idiopathic pulmonary fibrosis: evidence-based guidelines for diagnosis and management. Am J Respir Crit Care Med. 2011; 183:788-824

7. Schwartz DA, Helmers RA, Galvin JR, Van Fossen DS, Frees KL, Dayton CS, et al. Determinants of survival in idiopathic pulmonary fibrosis. Am J Respir Crit Care Med. 1994;149:450-4.

8. Mapel DW, Hunt WC, Utton R, Baumgartner KB, Samet JM, Coultas DB. Idiopathic pulmonary fibrosis: survival in population based and hospital based cohorts. Thorax. 1998;53:469-76.

9. Saito Y, Kawai Y, Takahashi N, Ikeya T, Murai K, Kawabata Y, et al. Survival after surgery for pathologic stage IA non-small cell lung cancer associated with idiopathic pulmonary fibrosis. Ann Thorac Surg. 2011;92:1812-7.

10. Watanabe A, Higami T, Ohori S, Koyanagi T, Nakashima S, Mawatari T. Is lung cancer resection indicated in patients with idiopathic pulmonary fibrosis? J Thorac Cardiovasc Surg. 2008;136:1357-63. 63 e1-2.

11. Watanabe A, Kawaharada N, Higami T. Postoperative acute exacerbation of IPF after lung resection for primary lung cancer. Pulm Med. 2011;2011:960316.

12. Fujimoto T, Okazaki T, Matsukura T, Hanawa T, Yamashita N, Nishimura K, et al. Operation for lung cancer in patients with idiopathic pulmonary fibrosis: surgical contraindication? Ann Thorac Surg. 2003;76:1674-8.

13. Chiyo M, Sekine Y, Iwata T, Tatsumi K, Yasufuku K, Iyoda A, et al. Impact of interstitial lung disease on surgical morbidity and mortality for lung cancer: analyses of short-term and long-term outcomes. J Thorac Cardiovasc Surg. 2003;126:1141-6.

14. Kawasaki H, Nagai K, Yoshida J, Nishimura M, Nishiwaki Y. Postoperative morbidity, mortality, and survival in lung cancer associated with idiopathic pulmonary fibrosis. J Surg Oncol. 2002;81:33-7.

15. Martinod E, Azorin JF, Sadoun D, Destable MD, Le Toumelin P, Longchampt E, et al. Surgical resection of lung cancer in patients with underlying interstitial lung disease. Ann Thorac Surg. 2002;74:1004-7.

16. Okamoto T, Gotoh M, Masuya D, Nakashima T, Liu D, Kameyama K, et al Clinical analysis of interstitial pneumonia after surgery for lung cancer. Jpn J Thorac Cardiovasc Surg. 2004;52:323-9.

17. Sawabata N, Miyaoka E, Asamura H, Nakanishi Y, Eguchi K, Mori M, et al Japanese lung cancer registry study of 11,663 surgical cases in 2004: demographic and prognosis changes over decade. J Thorac Oncol. 2011;6:1229-35.

18. Nishiyama O, Taniguchi H, Kondoh Y, Kimura T, Kato K, Kataoka K, et al. A simple assessment of dyspnoea as a prognostic indicator in idiopathic pulmonary fibrosis. Eur Respir J. 2010;36:1067-72.

19. Celli BR, MacNee W, ATS/ERS Task Force. Standards for the diagnosis and treatment of patients with COPD: a summary of the ATS/ERS position paper. Eur Respir J. 2004;23:932-46.

20. Hamada K, Nagai S, Tanaka S, Handa T, Shigematsu M, Nagao T, et al. Significance of pulmonary arterial pressure and diffusion capacity of the lung as prognosticator in patients with idiopathic pulmonary fibrosis. Chest. 2007;131:650-6.

21. Kutlu CA, Williams EA, Evans TW, Pastorino U, Goldstraw P. Acute lung injury and acute respiratory distress syndrome after pulmonary resection. Ann Thorac Surg. 2000;69:376-80.

22. Myrdal G, Gustafsson G, Lambe M, Horte LG, Stahle E. Outcome after lung cancer surgery. Factors predicting early mortality and major morbidity. Eur J Cardiothorac Surg. 2001;20:694-9.

23. Nishiyama O, Taniguchi H, Kondoh Y, Kimura T, Kato K, Ogawa T, et al Dyspnoea at 6-min walk test in idiopathic pulmonary fibrosis: comparison with COPD. Respir Med. 2007;101:833-8.

\section{Discussion}

Dr Chukwumere Nwogu (Buffalo, NY). Dr Date, I congratulate you and your colleagues for conducting such a large multi-institutional study. This study provides us with some guidance for decision-making in this difficult group of patients. We typically approach these patients with trepidation as we evaluate them for possible surgical resection. I appreciate the provision of the article and slides before your presentation.

I have 3 questions for you. Before the identification of some risk factors in this study, what specific selection criteria did the surgeons in your consortium use to select the surgical procedures that were offered to your patients, for instance, segmentectomy versus lobectomy? How were those decisions made?

Dr Date. Regarding the selection criteria during this period, this decision was entirely up to the individual institution. This is a retrospective multicenter trial.

Dr Nwogu. In your institution, how did you make that decision?

Dr Date. First, we discussed with the medical oncologists and radiologists whether the patient should be taken to the operating room or not, and then if we decided to perform surgery, we looked at the pulmonary function, quality of life, and so on, and then we decided, but this was probably more of a subjective assessment at that time.

Dr Nwogu. You chose a \%VC of $80 \%$ as a threshold to decide who should undergo surgery or as a cutoff to decide who would be a favorable candidate, but it seems you did not take into consideration the volume of lung to be resected. Did you look into other parameters, such as the predicted postoperative percent forced vital capacity (FVC) or the predicted postoperative percent DLCO. It seems to me that the risk would be less in a patient in whom you would be able to perform a complete resection with 
segmentectomy versus a bilobectomy, for instance. Did you take into consideration the volume of lung to be resected?

Dr Date. That is a great suggestion. We have not looked at our data in that way yet. We will, after your suggestion. I assume that when the postoperative \% VC is low, the result is going to be very bad, but we have not done that analysis yet.

Dr Nwogu. Now that you have this information, how has it affected your practice? How do you balance the tradeoff between higher AE of ILD in the larger resections versus the markedly improved long-term survival in those patients? How do you make that decision now?

Dr Date. Regarding the current practice, the decision is still made on a patient-by-patient basis. However, now that we know the 7 risk factors for AE and 5 independent predictors of survival, we can select the optimal surgical procedure for each patient more objectively than before. Regarding bilobectomy or pneumonectomy, a bigger operation, we looked at the rate of $\mathrm{AE}$, and it was 5 to 7 times more than lobectomy and the long-term survival was disappointing. Therefore, for patients requiring a bigger operation (eg, bilobectomy or pneumonectomy), the surgical option should be limited.

Dr Thomas Egan (Chapel Hill, NC). You chose 80\% FVC. With such a large number, were you able to look at different thresholds and come up with a suggestion that $80 \%$ was an important threshold or was it just chosen as one item to look at?

Dr Date. Honestly, $80 \%$ was chosen because $80 \%$ is usually used for restrictive disease, and we found that there was a significant difference. That is why we chose that number.

Dr Egan. The reason I ask is because it seems to me that there is probably an FVC threshold where the stage I cases would be better served by another modality, like stereotactic radiosurgery.

Dr Date. That is a good suggestion.

Dr Daniel Miller (Marietta, $G a$ ). Were you able to look at the perioperative events that occurred, especially bronchopleural fistula, prolonged air leak, and empyema? We all know that when we operate on patients with ILD, they have a more complicated course. Did that play a major role in the acute respiratory failure during that early recovery period and did that make a difference?

Dr Date. We collected those data and found that the postoperative events, such as prolonged air leak, infection, and so on, can trigger the $\mathrm{AE}$ as well, but we wanted to know the preoperative factors that could predict the outcome. Those kind of events occurred after the surgery, and the decision-making is difficult before the surgery.

Dr Miller. Was there a difference between the approach, either video-assisted thoracoscopic surgery or a thoracotomy? Sometimes with these patients, as you know, they are difficult from the standpoint that you have to do a lot of these open.

Dr Date. Approximately $45 \%$ of the patients received this operation by video-assisted thoracoscopic surgery and $55 \%$ by open thoracotomy. There was no difference between the 2 groups in terms of $\mathrm{AE}$ and no difference in survival.

Dr Robert Cerfolio (Birmingham, Ala). I have 2 quick questions and a comment. I am surprised you didn't mention pulmonary artery hypertension or assessment of that by echocardiography. Maybe it's different in the United States, but we don't operate in most of these patients because of pulmonary artery hypertension. Did you look at that?

Dr Date. No, we did not look at that because these are the patients who were found to have ILD during the workup phase of lung cancer itself. We believe these are in the very early phase of fibrosis.
Dr Cerfolio. The second question is technical tricks to take the fissure. These fissures are nightmares. They are big and thick. Just quickly tell us some tricks on how you took the thick fissure, especially if you are doing a right upper lobe, the fissure between the upper and the middle.

Dr Date. That is probably a question to my personal experience. We try not to go into the fissure at first. We try to divide the vessels.

Dr Cerfolio. We understand that you do the fissures last.

Dr Date. Yes.

Dr Cerfolio. How do you take them?

Dr Date. We usually use a stapler.

Dr Cerfolio. Which stapler? They are very thick.

Dr Murthy. You're thinking of a different animal. These are patients who have been described on CT scan as having some evidence of ILD.

Dr Cerfolio. So you don't think that they are the real bad ones that we're talking about.

Dr Murthy. Well, you have an FVC greater than $80 \%$ predicted in $80 \%$ of their study population. The entrance criteria is purely radiographic for this study and appears to be independent of positron emission tomography or functional criteria.

Dr Cerfolio. So they didn't clinically have thick fissures.

Dr Murthy. I doubt it. It's not the type of case you're thinking about of more end-stage disease.

Dr Cerfolio. That's important for us to know in the audience, because those patients don't do well with surgery. The third thing is that I would invite you to look at stereotactic body radiation therapy versus this for the T1As if they really do have significant pulmonary fibrosis.

Dr Sudish Murthy (Cleveland, Ohio). Another difference I think the audience has to understand is that when you are looking at percent predicted forced expiratory volume in 1 second (FEV1) and you have a homogeneous population from whom you are getting your norms and you are comparing it with a homogeneous population, it's easy to translate, but in the United States, if you take a standard FEV1 of $80 \%$ as being something that is grossly abnormal, it depends on the ethnicity of the person who is getting the spirometry checked. A small East Indian male will have a predicted FVC of $65 \%$ or $70 \%$, but he may have totally normal spirometry if he would have had his spirometries done in India. I wouldn't get hung up on the $80 \%$ FVC. That is another misleading piece of information.

Dr Ara Vaporciyan (Houston, Tex). The decision on the surgical approach was not set in advance because this was a retrospective study, so could a reason for the wedge resection in the patients with high FEV1 be that those patients had a higher disease stage and were being forced into a wedge resection because of concern about their interstitial disease. Likewise, in the lower than $80 \%$ group, could those patients have received a wedge resection because they had horrific FEV1, very low, and so the differences in the survival patterns of the wedge resections are due to the bias introduced by the surgeon's decision and differences in stage and FEV1?

Dr Date. That is true, but we did a multivariate analysis that still showed a difference between the 2 groups. I think there is a bias, but that can be overcome by an analysis in a multivariate way.

Dr Vaporciyan. I would warn you that when 2 factors in a multivariable analysis track parallel one another, you can get fooled.

Dr Date. Yes. You may need a randomized prospective trial to prove that. 
TABLE E1. Univariate analysis for patients' survival

\begin{tabular}{|c|c|c|c|c|c|c|}
\hline Factors & Categories & Cases & Hazard ratio & $95 \%$ CI & $P$ value & $\begin{array}{c}P \text { value of global } \\
\text { association }\end{array}$ \\
\hline Age & & 1763 & 1.013 & $1.003-1.024$ & .009 & \\
\hline \multirow[t]{2}{*}{ Sex } & Male & 1593 & 1 & - & - & \\
\hline & Female & 170 & 0.659 & $0.504-0.861$ & .002 & \\
\hline BMI & & 1746 & 0.973 & 0.951-0.996 & .022 & \\
\hline \multirow[t]{3}{*}{ Smoking history } & Never smoked & 109 & 1 & - & - & .006 \\
\hline & Ex-smoker & 1006 & 1.649 & $1.170-2.326$ & .004 & \\
\hline & Current smoker & 632 & 1.428 & $1.004-2.032$ & .048 & \\
\hline Brinkman index & & 1742 & 1.000 & $1.000-1.000$ & .302 & \\
\hline \multicolumn{7}{|l|}{ Comorbidities } \\
\hline \multirow[t]{2}{*}{ Asthma } & - & 1742 & 1 & - & - & \\
\hline & + & 33 & 0.838 & $0.484-1.450$ & .527 & \\
\hline \multirow[t]{2}{*}{ Emphysema } & - & 1167 & 1 & - & - & \\
\hline & + & 589 & 1.084 & $0.933-1.259$ & .294 & \\
\hline \multirow[t]{2}{*}{ Collagen disease } & - & 1654 & 1 & - & - & \\
\hline & + & 102 & 1.123 & $0.849-1.485$ & .416 & \\
\hline \multirow[t]{3}{*}{ KL6* (U/mL) } & & 1043 & 1.000 & $1.000-1.000$ & .002 & \\
\hline & $<1000$ & 834 & 1 & - & - & \\
\hline & $>1000$ & 209 & 1.431 & $1.157-1.769$ & $<.001$ & \\
\hline CEA (ng/mL) & & 1664 & 1.001 & $1.000-1.002$ & .005 & \\
\hline $\mathrm{PAO}_{2}$ (torr) & & 1552 & 0.998 & 0.991-1.004 & .493 & \\
\hline $\mathrm{PaCO}_{2}$ (torr) & & 1547 & 0.979 & $0.961-0.998$ & .030 & \\
\hline \multirow[t]{3}{*}{$\% \mathrm{VC}$} & & 1741 & 0.977 & 0.973-0.982 & $<.001$ & \\
\hline & $<80$ & 263 & 1 & - & - & \\
\hline & $>80$ & 1478 & 0.516 & $0.431-0.617$ & $<.001$ & \\
\hline FEV1 (L) & & 1748 & 0.739 & $0.645-0.847$ & $<.001$ & \\
\hline \multirow[t]{3}{*}{ FEV1.0\% } & & 1749 & 1.006 & $1.001-1.012$ & .024 & \\
\hline & $<70$ & 460 & 1 & - & - & \\
\hline & $>70$ & 1289 & 1.301 & $1.100-1.539$ & .002 & \\
\hline$\%$ FEV 1.0 & & 1742 & 0.997 & 0.994-1.001 & .122 & \\
\hline $\operatorname{DLCO}(\mathrm{mL} / \mathrm{min} / \mathrm{torr})$ & & 1121 & 0.960 & $0.943-0.978$ & $<.001$ & \\
\hline$\%$ DLCO & & 1128 & 0.993 & 0.989-0.997 & $<.001$ & \\
\hline \multirow[t]{2}{*}{ Radiologic findings } & UIP pattern & 1300 & 1 & - & - & \\
\hline & Non-UIP pattern & 463 & 0.836 & $0.706-0.988$ & .036 & \\
\hline \multirow[t]{4}{*}{ Histology } & Adenocarcinoma & 721 & 1 & & & $<.001$ \\
\hline & Squamous cell & 816 & 1.172 & $1.005-1.366$ & .042 & \\
\hline & Large cell & 64 & 1.071 & $0.722-1.587$ & .734 & \\
\hline & Others & 139 & 1.440 & $1.107-1.874$ & .007 & \\
\hline \multirow[t]{7}{*}{ Pathologic stage } & Ia & 547 & 1 & - & - & \\
\hline & $\mathrm{Ib}$ & 481 & 1.548 & $1.255-1.909$ & $<.001$ & \\
\hline & IIa & 70 & 1.723 & $1.178-2.521$ & .005 & \\
\hline & $\mathrm{IIb}$ & 241 & 2.203 & $1.741-2.787$ & $<.001$ & \\
\hline & IIIa & 244 & 3.020 & $2.405-3.791$ & $<.001$ & \\
\hline & $\mathrm{IIIb}$ & 114 & 3.264 & $2.464-4.324$ & $<.001$ & \\
\hline & IV & 34 & 4.036 & $2.663-6.116$ & $<.001$ & \\
\hline \multirow[t]{3}{*}{ Surgical procedures } & Wedge resection & 275 & 1 & - & - & $<.001$ \\
\hline & Segmentectomy/lobectomy & 1386 & 0.840 & $0.694-1.018$ & .076 & \\
\hline & Bilobectomy/pneumonectomy & 94 & 1.440 & $1.056-1.965$ & .021 & \\
\hline \multirow[t]{4}{*}{ Tumor location } & Upper lobe & 670 & 1 & - & - & .028 \\
\hline & Middle lobe & 77 & 1.372 & $0.963-1.953$ & .080 & \\
\hline & Lower lobe & 958 & 1.249 & $1.072-1.456$ & .004 & \\
\hline & Multiple & 5 & 0 & N/A & N/A & \\
\hline \multirow[t]{2}{*}{ VATS } & - & 964 & 1 & - & - & \\
\hline & + & 798 & 0.952 & $0.825-1.099$ & .500 & \\
\hline
\end{tabular}


TABLE E1. Continued

\begin{tabular}{|c|c|c|c|c|c|c|}
\hline Factors & Categories & Cases & Hazard ratio & $\mathbf{9 5} \% \mathbf{C I}$ & $P$ value & $\begin{array}{c}P \text { value of global } \\
\text { association }\end{array}$ \\
\hline \multirow[t]{3}{*}{ Node dissection } & 0 & 311 & 1 & - & - & .680 \\
\hline & 1 & 339 & 0.919 & $0.723-1.167$ & .487 & \\
\hline & 2 & 1104 & 0.921 & $0.762-1.113$ & .394 & \\
\hline
\end{tabular}

BMI, Body mass index; $C E A$, carcinoembryonic antigen; $C I$, confidence interval; $D L C O$, carbon monoxide diffusing capacity; $F E V I$, forced expiratory volume in 1 second; $K L-6$, Klebs von Lungen-6; N/A, not available; $\mathrm{PaCO}_{2}$, arterial carbon dioxide tension; $\mathrm{PAO}_{2}$, arterial oxygen tension; UIP, usual interstitial pneumonia; VATS, video-assisted thoracoscopic surgery; $\% V C$, percent vital capacity. *Serum biomarker for pulmonary fibrosis. 